\title{
Passive Congregation Theory for Particle Swarm Optimization (PSO): an Application in Reservoir System Operation
}

\author{
Md. Shabbir Hossain ${ }^{1}$, Lariyah Bte Mohd Sidek ${ }^{2}$, Mohammad Marufuzzaman ${ }^{3}$, M. H. Zawawi ${ }^{4}$ \\ ${ }^{124}$ Civil Engineering Department, Institute of Energy Infrastructure, Universiti Tenaga Nasional (Putrajaya Campus), \\ Kajang, Malaysia, 43000. \\ ${ }^{3}$ Sustainable Technology \& Environment Group, Institute of Energy Infrastructure, Universiti Tenaga Nasional, 43000, \\ Kajang, Selangor, Malaysia \\ *Corresponding author E-mail: mdshabbir@uniten.edu.my
}

\begin{abstract}
Particle swarm optimisation (PSO) is a very well-known method and has a strong background in optimisation filed to solve different nonlinear, complex problems especially in creating the reservoir release policies. This research modified the particle updating process of the standard PSO algorithm by including the passive congregation (PC) theory. The passive congregation theory of natural being's social behaviour is adopted to updated the standard PSO algorithm and used to develop and optimise a reservoir release policy for monthly basis. The inflow data to the dam/reservoir has categorised into three different categories (High, medium and low). The problem is formulated on correspondence to the release and capacity constraints. Water deficit from the release is aimed to be minimised and formulated as the main objective function. Monthly releases are taken as the main objective variables and are essentially control the water deficit of the process. The standard form of PSO then compared with the updated version and the results is analysed by adopting different performance measuring indicators such as reliability, vulnerability and resilience. The results showed that the updated PSO-PC is more capable of the standard PSO (5\% more reliable; 0.02 less vulnerable and 1.5 more resilience) in providing optimum results for a reservoir system.
\end{abstract}

Keywords: Reservoir release policy; Particle swarm optimisation, Swarm Intelligences.

\section{Introduction}

The reservoir release policy is created as a decision model by which the amount of water release is determined and retained the rest for future uses in a given time. The reservoir release policy is to design the model of water release as well as storage over the period considering the variations in inflows and demand. Reservoir release policy thus is very crucial and difficult as the increasing water demand of users and the variable natures of streamflow especially in tropical countries like Malaysia. Generally, the reservoir operations are implemented based on the current situations. The rules of the reservoir have instructed the operators to generate the policy in such a way that it fulfils the system requirements. However, as there are many feasible operating policies may exist, a mathematical optimisation technique is required.

Particle Swarm Optimization (PSO) belonged to the swarm intelligence (SI) family and known as a very popular tool in solving real-life optimisation problems. It can easily provide an optimal solution to any complex non-linear problem [1]. The simplicity and the applicability of PSO and the other SI techniques attract many researchers to use it in solving different hydrological problems (Gandomi et al. 2013).

The algorithm of PSO mimics the intelligent behaviour of a flock of birds moving around in search of food. The choreography of the flight allows the flock to share all the information about the food among themselves once any individual member discovers it. The flight direction and the velocity change over the shared information. This process of optimisation was first proposed by
Eberhart et al. [1], and according to their description, the social behaviour of the flock reflects the phenomena of comparing two important decision properties named as "local best" and "global best". Local best is the currently observed best decision for a particular food and the global best is the best decision found. Later, in 2004, He et al. [3] proposed to add the passive congregation factor with PSO velocity update. Based on the mathematical model given in [4], the aggregation can be referred to as a grouping of the organisms (such as- fish schooling, bird flocking) by external physical forces.

On the other hand, the congregation is defined as grouping by social forces in where the attraction source is the group itself. In the passive congregation theory, any individual group members attract the other, but they may show no social behaviour (global best). In these congregations, information may be transferred passively rather than actively [5]. Recent research works who considered optimisation methods in creating reservoir release policies showed that modified PSO would be an ideal optimisation technique for creating reservoir release policy [6-10]. Some other related works on reservoir hydrology can be found here- [11-19]. This research is intended to include passive congregation theory by updating the key properties of the particle movement (Velocity update) inside the standard PSO algorithm. Both, standard and the updated PSO is adopted and tested to optimise the release amount of a reservoir. The monthly releases are taken as decision variables limited by release constraints. The representation of the reservoir system is also taken to be subjected to the storage constraints and continuity through the consecutive months. The problem has been represented as a simple way that can be optimised by any 
improved population-based search algorithm. Also, the representation of the release policy is generated in such a manner that the decision maker could have a clear understanding for decision making on the release amount. For verification of the model, simulation has been undertaken, and the simulation results have been analysed using the risk analysis approach to compare the model's efficiency in minimising water deficit. The Klang Gates Dam (KGD) is considered as the case study in this research, which contributes as a water supplier for the domestic uses to the surroundings.

\section{Methodology}

Reservoir system operation: Mathematical Representation In any reservoir system operation, the authority usually faces two types of constraints in deciding on the release amount, bounds on release volume and keeping the water level within a safe operational zone. To maintain such configurations and requirements, the model is formulated in the following form -

The Objective or Fitness function is considered as the minimisation of water deficit, which is given in Equation 1,

$$
\operatorname{MinZ}=\sum_{t-1}^{12}\left(D_{t}-R_{t}\right)^{2}
$$

Here, the releases $(\mathrm{R})$ for any months $(\mathrm{t})$ must be within the upper and lower bounds as given in Equation 2,

$$
R_{t}-R_{\min } \geq 0 \text { and } R_{\max }-R_{t} \geq 0
$$

Also, the storages $(\mathrm{S})$ for any month ( $\mathrm{t})$ must be within the boundary as expressed in Equation 3,

$$
S_{t}-S_{\text {min }} \geq 0 \text { and } S_{\text {max }}-S_{t} \geq 0
$$

The continuity equation 4 should be satisfied for all the months (t) as,

$$
S_{(t+1)}=S_{t}+\text { Inflow }_{t}-R_{t}-\text { Losses }_{t}
$$

The concept of using a penalty function is based on adopting an extra parameter in addition to the objective function that controls the constraints and helps to eliminate the decision variables that cause a violation of any constraints. As equation (1) is representing a minimisation problem, the model always targets to obtain the minimum value of $\mathrm{Z}$. So, if any release amount caused the reservoir storage to violate the upper and lower limits, given in equation 3, then the penalty term will increase the value of $\mathrm{Z}$ based on the large multiples of violation magnitude. The release variables that responsible for increasing the value of $\mathrm{Z}$ is marked as weaker solutions (release decision) and eliminated to reach an optimum state.

Klang Gates Dam (KGD) is located at Taman Melawati, Malaysia. The geographical coordinates of the dam are $3^{\circ} 13^{\prime} 58^{\prime \prime}$ North (3.233 degrees) and $101^{\circ} 45^{\prime} 0 "$ East (101.75 degrees). The storage and the release constraints of the reservoir are given below.

- Storage constraint: The storage $\mathrm{S}$ in a month $\mathrm{t}$ is kept within the limit of dead storage and the capacity of the reservoir; 1648.67 $\leq \mathrm{St} \leq 6194 \mathrm{MG}$ (for $\mathrm{t}=$ Jan, Feb, ..., Dec).

- Release constraint: The water release amount $\mathrm{R}$ from the reservoir to meet the water demand of the area has a lower and upper bound, $868 \leq \mathrm{Rt} \leq 1379.50 \mathrm{MG}$ (for $\mathrm{t}=\mathrm{Jan}, \mathrm{Feb}, \ldots \ldots \ldots$. Dec).

Standard PSO in reservoir release optimisation

More likely to the other population-based algorithm, PSO starts with developing a random decision variable set. These random variables are called "particles", and a group of the variables are named as "swarm" (given in Equation 5 and 6). So, in a random release string consisting of 12 values of water volume to be released (R) from January to December, the 12 releases are considered to be particles and the population set of these particles is considered to be a swarm.

$$
\begin{aligned}
& \text { particles }=\left[R_{\text {jan }}, R_{\text {feb }}, \ldots \ldots . . ., R_{d e c}\right] \\
& \text { Where, } R_{\min } \leq R_{i} \leq R_{\max } \text { for } i=J a n, F e b, \ldots . . \text { Dec. }
\end{aligned}
$$

swarm $=\left[\begin{array}{c}\text { particle }_{1} \\ \text { particle }_{2} \\ \bullet \\ \bullet \\ \text { particle }_{\text {popsize }}\end{array}\right]$

$[\text { swarm }]_{(\text {popsize } n \text { nvar })}=\left(R_{\max }-R_{\min }\right) \times[r]_{(\text {popsize } n \text { var })}+R_{\min }$

where,

popsize $=$ population or swarm size

nvar $=$ total number of variables

$r=$ random number (between 0 to 1 ).

Equation (7) is used in this study to generate the initial swarm for the PSO algorithm to execute. Equation (8) (known as the velocity update) controls the swarm's movements through the searching pool for the optimum solutions. In each iteration, the algorithm records the local optima and compares it with the global (best solution yet) optima. However, the criteria for being chosen as an optimum state depend on the fitness of the objective function.

Any solutions in the swarm (decision variables: releases) calculate and remember their own fitness for their position in next iteration. The position of any particle is accelerated towards the global best position by using equation (8) and (9). In any search step t, the ith particle uses to update its candidate solution's current position $\left(\mathrm{v}_{\mathrm{ij}}{ }^{\mathrm{t}}\right)$ by using local best $\left(\mathrm{p}_{\mathrm{ij}}{ }^{\mathrm{t}}\right)$ and global best $\left(\mathrm{p}_{\mathrm{gj}}{ }^{\mathrm{t}}\right)$ position achieved yet.

$v_{i j}^{t+1}=w v_{i j}^{t}+\phi_{1} r_{1}^{t}\left(p_{i j}^{t}-R_{i j}^{t}\right)+\phi_{2} r_{2}^{t}\left(p_{g j}^{t}-R_{i j}^{t}\right)$

$R_{i j}^{t+1}=v_{i j}^{t+1}+R_{i j}^{t}$

where,

$v_{i j}^{t+1} \quad=$ velocity measures for the particles

$w=$ inertial weight; control the velocity direction

$\phi_{1} \& \phi_{2}=$ acceleration coefficient; should be $>1$ (mostly taken as 2)

$r_{1}^{t} \& r_{2}^{t}=$ random numbers; uniformly distributed between $0-1$

$R_{i j}^{t}=$ position of any particle at $\mathrm{t}$

$p_{i j}^{t}=$ best-suggested release (providing lowest $\mathrm{Z}$ ) at $\mathrm{t}$

$p_{g j}^{t}=$ best-suggested release (providing lowest $\mathrm{Z}$ ) achieved yet.

After generating the initial population (randomly generated monthly release options within the release boundary), the velocity update provides a new direction to the particles. A new position could be reached by this updated velocity parameter, as given in Equation 9. The fitness $\mathrm{Z}$ is calculated by using the objective function (Equation 1) including the penalty term for constraint violation. The best position of the particle is saved as the local best and would be compared with the global best achieved yet. The whole population (swarm) then turns towards the current best position until it finds another better solution than the current one. 
An iteration number need to be fixed at the beginning of the algorithm as the stopping criteria of the total iteration process.

Updated PSO with passive congregation theory

The passive congregation theory can be adopt in standard PSO by adding an extra information randomly from the previous population and make sure that the position is shifting accurately towards the global best.

In equation 8 , the third parameter $\phi_{2} r_{2}^{t}\left(p_{g j}^{t}-R_{i j}^{t}\right)$ is classified as active congregation [3]. To adopt the passive aggregation theory $\mathrm{He}$, et al. proposed adding another term to keep the model simple and uniform. The modified velocity function is given in equation 10 ,

$v_{i j}^{t+1}=w v_{i j}^{t}+\phi_{1} r_{1}^{t}\left(p_{i j}^{t}-R_{i j}^{t}\right)+\phi_{2} r_{2}^{t}\left(p_{g j}^{t}-R_{i j}^{t}\right)+\phi_{3} r_{3}^{t}\left(X_{g j}^{t}-R_{i j}^{t}\right)[10]$ where,

$X_{i j}^{t+1}=$ randomly selected particle from the swarm

$\phi_{3}=$ passive congregation coefficient

$r_{3}^{t}=$ random numbers; uniformly distributed between $0-1$

\section{Result and Discussion}

The release amount from the reservoir depends on the inflow category, operational time period (monthly) and current reservoir storage or water level. For each inflow category, the release policies have been given for every month considering the storage condition as input parameter. With this release curve one is able to decide on how much water release would be optimum for a particular month of the year to minimize the water deficit properly. The optimal release options for the month of July are given in figure 1 ( $a, b$ and c).

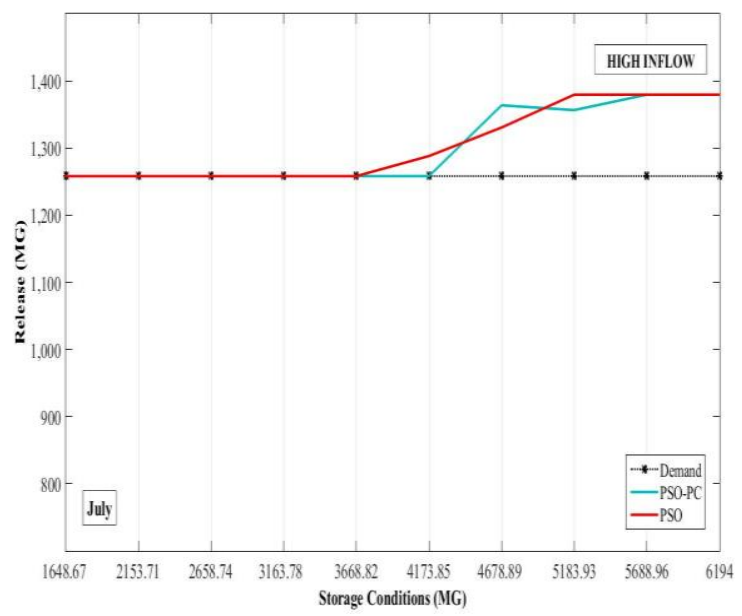

(a) High Inflow condition.

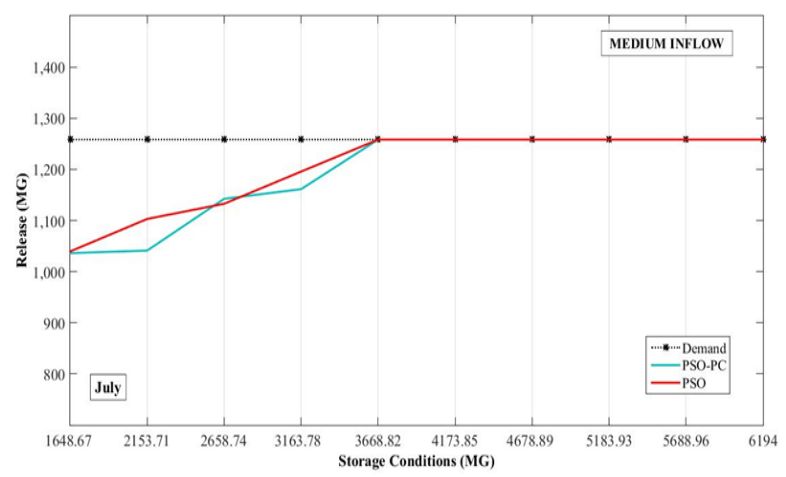

(b) Medium Inflow condition.

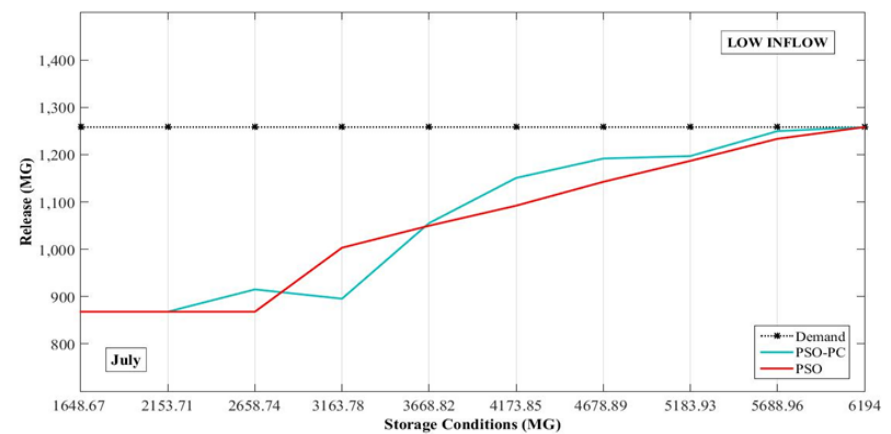

(c) Low inflow condition.

Fig 1: Optimum release under different inflow pattern.

The release amount depends on the inflow patterns, operational time (in this case- monthly) and current water level of the dam. For each inflow category, the release decision has been suggested for every month considering the current storage condition as an input parameter. With this release policy, one should be able to calibrate the amount of released water that would be optimum with minimum water deficit for a month. The optimal release curves for the month of July are given in Figure 1.

To check the model efficiency, a very classical approach is adopted. Three performance measuring index, Reliability [20], Resiliency [21] and Vulnerability [21] from the simulated results is computed and compared. More detailed equations for these indices are given in Table 1 .

Table 1: Performance measuring indices

\begin{tabular}{|c|c|c|}
\hline \multirow{2}{*}{ Index } & \multicolumn{2}{|l|}{ Model validation } \\
\hline & Equations & Variables \\
\hline $\begin{array}{l}\text { Volumetric }(\mathrm{Rv}) \\
\text { and Periodic }(\mathrm{Rp}) \\
\text { reliability }\end{array}$ & $\begin{array}{l}R_{v}=(v / V) \times 100 \% ; \\
R_{p}=(n / N) \times 100 \%\end{array}$ & $\begin{array}{l}\mathrm{v}=\text { volume of } \\
\text { water releases } \\
\text { (model output) } \\
\mathrm{V}=\text { volume of } \\
\text { targeted de- } \\
\text { mand } \\
\mathrm{n}=\text { total no. of } \\
\text { time period } \\
\text { meeting the } \\
\text { targeted de- } \\
\text { mand (in } \\
\text { months) } \\
\mathrm{N}=\text { total no. } \\
\text { considered time } \\
\text { period (in } \\
\text { months) }\end{array}$ \\
\hline Resilience (Rs) & $\mathrm{R}_{s}=\frac{N S}{N T}$ & $\begin{array}{l}\text { NS = no. of } \\
\text { satisfied (zero } \\
\text { deficit) time } \\
\text { period followed } \\
\text { an shortage } \\
\text { NT = no. of } \\
\text { total shortage } \\
\text { period }\end{array}$ \\
\hline Vulnerability (V) & $\begin{array}{l}\mathrm{V}=\frac{1}{m} \times \sum_{t=1}^{N}\left[\max \left(0, D_{t}-R_{t}\right)\right] \\
\text { for } t=1,2, \ldots . . N\end{array}$ & $\begin{array}{l}\mathrm{m}=\text { no. of } \\
\text { model failure } \\
\text { period (water } \\
\text { deficit } \neq 0 \text { ) } \\
\mathrm{N}=\text { total time } \\
\text { period consid- } \\
\text { ered for simula- } \\
\text { tion (in months) } \\
\mathrm{D}=\text { targeted } \\
\text { demand } \\
\mathrm{R}=\text { water } \\
\text { release (model } \\
\text { output). }\end{array}$ \\
\hline
\end{tabular}

The actual inflow and storage data of the KGD is fed to the release curves and the return release amounts from the curves are recorded for that month. This simulation process is done as a continuous process for 264 consecutive months (22 years of actual 
data). Then the final storage was calculated by using the continuity equation and used as an initial storage for the next consecutive month. The simulation steps for a total considered time period $\mathrm{T}$ are given in figure 2 .

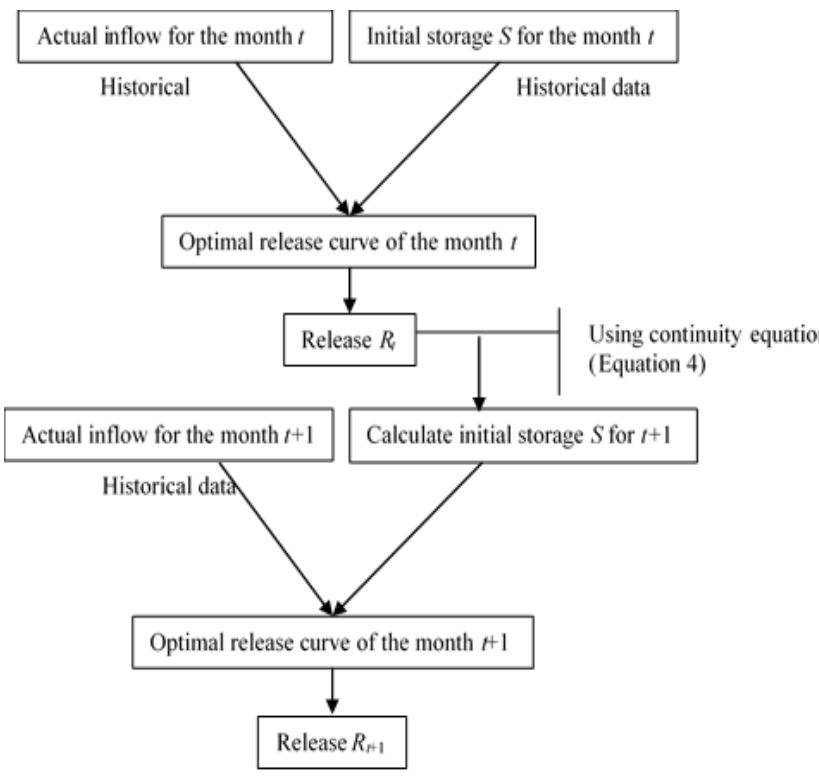

The process continues for the all-time

$$
\text { period: }
$$$$
t, t+1, t+2 \ldots \ldots \ldots, T
$$

Fig. 2: Simulation process by using historical data

\begin{tabular}{|c|c|c|c|c|}
\hline 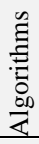 & $\begin{array}{c}\text { More Than } \\
\text { Demand }\end{array}$ & $\begin{array}{l}\text { Meet The } \\
\text { Demand }\end{array}$ & $\begin{array}{c}\text { Less than } \\
\text { demand }\end{array}$ & $\begin{array}{c}\text { Vulnerability } \\
\text { (V) }\end{array}$ \\
\hline $\begin{array}{l}0 \\
0 \\
0 \\
\mathscr{1}\end{array}$ & $\begin{array}{c}12 \% \\
\text { (30 times) }\end{array}$ & $\begin{array}{c}62.1 \% \\
\text { (164 times) }\end{array}$ & $\begin{array}{c}26.31 \% \\
\text { (70 times) }\end{array}$ & 0.65 \\
\hline$\stackrel{0}{\curvearrowleft}$ & $\begin{array}{c}12.1 \% \\
\text { (32 times) }\end{array}$ & $\begin{array}{c}59.47 \% \\
\text { (127 times) }\end{array}$ & $\begin{array}{c}28.41 \% \\
\text { (75 times) }\end{array}$ & 0.67 \\
\hline
\end{tabular}

The vulnerability (V) of each model is calculated by using the vulnerability equation (reported as $\mathrm{V}$ in Table 1) and the results are reported in Table 2 . From the simulation results of the both model, PSO-PC is less vulnerable than PSO as it achieved less value of $V$.

Table 3: . Resiliency measures from the simulation

\begin{tabular}{|c|c|c|}
\hline Measures & PSO-PC & PSO \\
\hline $\begin{array}{c}\text { Resilience } \\
\left(\mathrm{R}_{\mathrm{s}}\right)\end{array}$ & 15.5 & 14 \\
\hline $\begin{array}{c}\text { Max. no. of } \\
\text { consecutive } \\
\text { shortage }\end{array}$ & 1 & 1 \\
\hline
\end{tabular}

The other effective performance indicator is resiliency [21], the recovering capability of a model from a failure. In this case the failure is considered as failed to release more/less water than required. The resilience equation (given in Table 1) has been used to compute the resilience of both optimization model from the simulated release. Also, the maximum number of consecutive shortage period (release less than demand) has been calculated and reserved for resilience measures. The resilience analysis of these two models are provided in Table 3 . This case PSO-PC performed slightly better as it shows larger $R s$ value (1.5 more than standard PSO). Also, the maximum number of consecutive shortage period achieved is 1 , same in both optimization algorithm.

From these analysis, it seems that PSO-PC is more capable of providing optimum release for a reservoir system than PSO. The standard PSO was also a very good optimizer but PSO-PC performed better in terms of reliability, resiliency and vulnerability. The Resilience and the vulnerability is very important as it could be very crucial during any critical climatic situations.

\section{Conclusion}

To optimize the reservoir release for Klang Gate Dam The PSOPC was used which is the improvement of the standard PSO by adopting passive congregation theory in particle movement. The development in the algorithm was tested in optimizing the Klang Gates Dam release policy. The primary objective of this study was to use this both version of PSO to optimize the reservoir release of KGD and compare the simulation results by adopting performance measuring index. These basic performance indicators were- Reliability, Resilience and vulnerability. As reported earlier in the paper, all three indicators are indicating that both PSO performed very well in handling reservoir system but PSO-PC is more capable (5\% more reliable; 0.02 less vulnerable and 1.5 more resilience) in providing optimum results for a reservoir system.

\section{Acknowledgement}

The research is funded by the "Bold Grant" of University Tenaga Nasional (10289176/B/9/2017/57). The authors are grateful to the Civil engineering department and Institute of Energy Infrastructure of University Tenaga Nasional.

\section{References}

[1] Eberhart, R. C., Shi, Y., Kennedy, J. Swarm intelligence. Elsevier. (2001)

[2] Gandomi, A. H., Yang, X. S., Talatahari, S., Alavi, A. H. Metaheuristic algorithms in modeling and optimization. In Metaheuristic applications in structures and infrastructures, 1-24. (2013)

[3] He, S., Wu, Q.H., Wen, J.Y., Saunders, J.R. and Paton,R.C. A particle swarm optimizer with passive congregation. Bio Systems, 78(1-3), 135-147. (2004).

[4] Parrish, J.K. and Hamner,W.M. Animal Groups in Three Dimensions. Cambridge University Press, Cambridge, UK. (1997).

[5] Magurran, A.E.and Higham, A. Information transfer across fish shoals under predator threat. Ethology, 78(2), 153-158. (1988).

[6] Hossain, M.S., El-Shafie, A., Mahzabin, M.S., Zawawi, M.H. System performances analysis of reservoir optimization-simulation model in application of artificial bee colony algorithm. Neural Computing and Applications, 1-12. (2016a). doi: 10.1007/s00521016-2798-2

[7] Hossain, M.S., El-Shafie A., Mohtar, W.H.M.W. Application of intelligent optimization techniques and investigating the effect of reservoir size in calibrating the reservoir operating policy. Water Policy, 17 (6), 1143-1162. (2015).

[8] MS Hossain, A Reservoir Release Optimization-Simulation Model Using Particle Swarm Optimization (PSO) Algorithm. Journal of Engineering and Applied Sciences 100(10): 2186-2192. (2016b)

[9] Mohammed Falah Allawi, Othman Jaafar, Firdaus Mohamad Hamzah, Mohammad Ehteram, Md Shabbir Hossain, Ahmed ElShafie. Operating a reservoir system based on the shark machine learning algorithm. Environmental Earth Sciences, 77(10): 366. Doi: 10.1007/s12665-018-7546-8. (2018)

[10] Md S Hossain, A El-Shafie. Optimal operation of Klang gate dam using genetic algorithm. Jurnal Teknologi (Sciences and Engineering), 65(2): 37-40. (2013)

[11] Lariyah, M.S., Mohiyaden, H.A., Hayder, G., Hayder, G., Hussein, A., Basri, H., Sabri, A.F. And Noh, M.N. Application of Moving 
Bed Biofilm Reactor (MBBR) and Integrated Fixed Activated Sludge (IFAS) for Biological River Water Purification System: A Short Review, IOP Conference Series: Earth and Environmental Science 2016a.

[12] Sidek L, Basri H, Lee LK, Foo KY. The performance of gross pollutant trap for water quality preservation: a real practical application at the Klang Valley, Malaysia. Desalination and Water Treatment. 7;57(52):24733-41. (2016b)

[13] Hafiz I, Nor N.D.M, Sidek L.M, Basri H, Hanapi M.N, Livia L, Application of Integrated Flood Analysis System (IFAS) for Dungun river basin,IOP Conference Series: Earth and Environmental Science, 16(1), Article number 012128. (2013)

[14] Hafiz, I., Sidek, L.M., Basri, H., Fukami, K., Hanapi, M.N., Livia, L. \& Jaafar, A.S. 2015, "Integrated flood analysis system (IFAS) for Kelantan river basin", IEEE 2nd International Symposium on Telecommunication Technologies, Article number 7238196, pp. 159-162.

[15] Che Ros F, Tosaka H, Sidek LM, Basri H., Homogeneity and trends in long-term rainfall data, Kelantan River Basin, Malaysia, Int J River Basin Management, 14(2), pp. 151-163. (2016)

[16] Chow MF, Abu Bakar MF, Sidek LM, Basri H. Effects of substrate types on runoff retention performance within the extensive green roofs, J Eng Appl Sci, 12(21), pp. 5379-5383. (2017)

[17] Razad AZ, Muda RS, Sidek LM, Azia IS, Mansor FH, Yalit R. Simulation of breach outflow for earthfill dam, IOP Conference Series: Earth and Environmental Science, 16(1), Article Number 012030. (2013)

[18] Nor Amira Binti Bahari Md. Shabbir Hossain. Industrial waste water treatment using bagasse as an adsorbent. Putrajaya International Built Environment, Technology and Engineering Conference (PIBEC2016), pp- 44-49, (2016).

[19] Al-Ani, I.A.R., Mohd Sidek, L. And Basri, N.E.A. Expert system for mitigating erosion and sedimentation due to stormwater during construction activities in Malaysia. European Journal of Scientific Research, 38(1), pp. 38-44. (2009)

[20] Wurbs R.A. Modelling and analysis of reservoir system operations. Prentice-Hall, Inc, Upper Saddle River, NJ, USA. (1996)

[21] Loucks, D. P., \& Van Beek, E. Water resource systems planning and management: An introduction to methods, models, and applications. Springer. (2017). 